This PDF is a selection from a published volume from the National Bureau of Economic Research

Volume Title: The Economic Consequences of Demographic Change in East Asia, NBER-EASE Volume 19

Volume Author/Editor: Takatoshi Ito and Andrew Rose, editors

Volume Publisher: University of Chicago Press

Volume ISBN: 0-226-38685-6

ISBN13: 978-0-226-38685-0

Volume URL: http://www.nber.org/books/ito_08-2

Conference Date: June 19-21, 2008

Publication Date: August 2010

Chapter Title: Japan’s Unprecedented Aging and Changing Intergenerational Transfers

Chapter Authors: Naohiro Ogawa, Andrew Mason, Amonthep Chawla, Rikiya Matsukura

Chapter URL: http://www.nber.org/chapters/c8160

Chapter pages in book: $(131-160)$ 


\title{
Japan's Unprecedented Aging and Changing Intergenerational Transfers
}

\author{
Naohiro Ogawa, Andrew Mason, Amonthep Chawla, \\ and Rikiya Matsukura
}

\subsection{Introduction}

In 2005 the total world population exceeded 6.5 billion people, which is almost double the size observed in 1965 (United Nations 2007). The annual growth rate of the world population, however, has been declining continuously during the past four decades; as opposed to its peak value of 2.02 percent during 1965 to 1970 , the current annual growth rate is estimated at 1.17 percent. With the emergence of slower population growth in the latter half of the twentieth century, the world demographic outlook of today is substantially different from the one of only a few decades ago.

Slowing global population growth has been induced primarily by a significant decline in fertility over the past few decades. From 1965 to 1970 , there were only eight countries with below-replacement fertility (a total fertility rate [TFR] of less than 2.1 children per woman), a number that increased to sixty-eight by the period of 2000 to 2005 . Moreover, in terms of the population share, as shown in figure 4.1, only 8.4 percent of the world's population

Naohiro Ogawa is a professor of economics at the Nihon University and its Population Research Institute. Andrew Mason is a professor of economics at the University of Hawaii at Manoa, and senior fellow of the East-West Center. Amonthep Chawla is a research specialist at the Thailand Development Research Institute (TDRI). Rikiya Matsukura is a researcher at the Nihon University Population Research Institute.

Research for this chapter was funded by two grants from the National Institute of Health, NIA R01-AG025488 and AG025247. This work was also supported by a grant obtained by the Nihon University Population Research Institute from the Academic Frontier Project for Private Universities, a matching fund subsidy from the Ministry of Education, Culture, Sports, Science and Technology (MEXT), 2006-2010. Furthermore, the authors are grateful to the UNFPA (RAS5P203) and the Japan Medical Association for their financial assistance. An earlier version of this chapter was presented at the NBER-TCER-KDI Conference on the Demographic Transition in the Pacific Rim, held during June 19-21, 2008, in Seoul, Republic of Korea. 


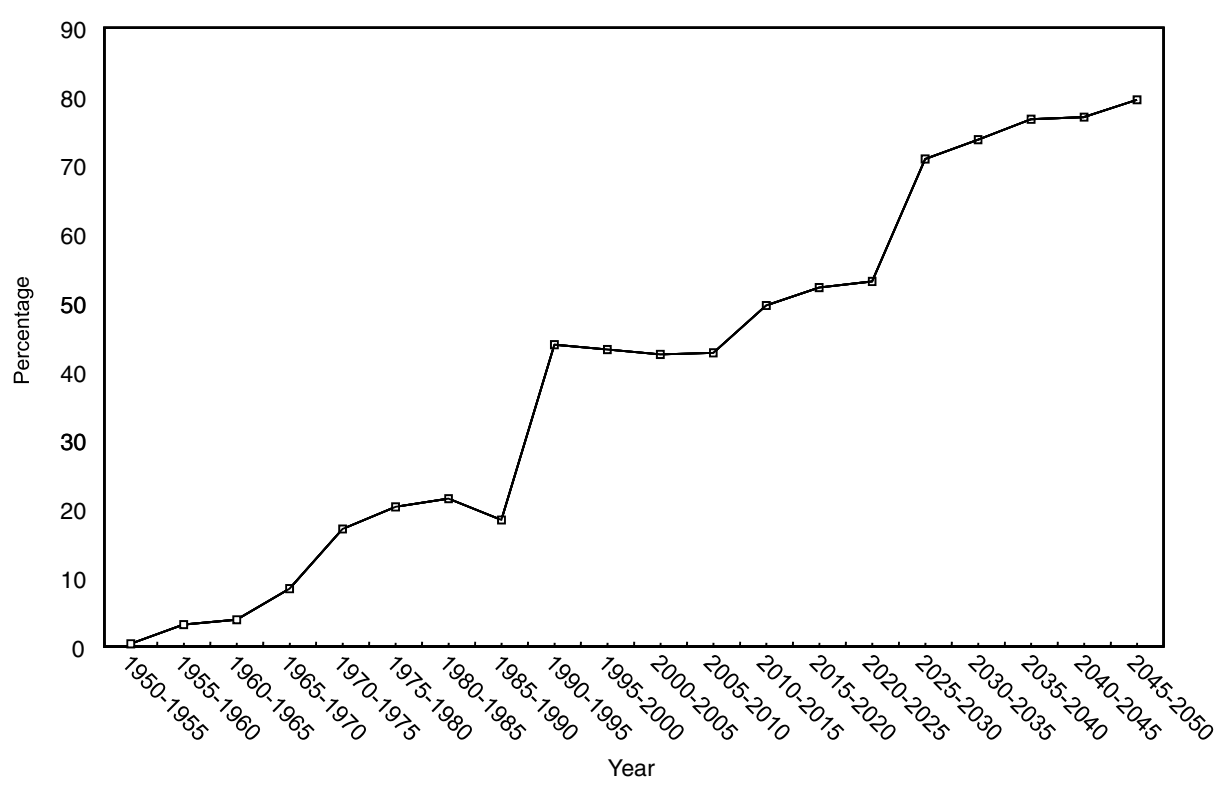

Fig. 4.1 Proportion of population with below-replacement fertility in the world population: 1950-2050

Source: United Nations (2007).

lived in countries with below-replacement fertility between 1965 and 1970, as compared to 42.7 percent from 2005 to 2010 . It is projected that more than half of the world population will live in countries with a fertility rate below the replacement level in the second half of the 2010s (United Nations 2007).

At present, the majority of these low-fertility countries are in the developed regions. It should be emphasized, however, that the number of countries in developing regions with below-replacement fertility has also been increasing at a phenomenal rate in recent years. It grew from nil to twenty-four developing countries/areas over the past four decades under consideration. Fourteen of these twenty-four countries/areas belong to Asia. Three Asian countries/areas with below-replacement fertility (Hong Kong, Macao, and the Republic of Korea) are currently classified in the category of lowest-low fertility (i.e., those with a TFR below 1.3). In fact, East Asia's fertility is now the lowest in the entire world (McDonald 2009).

Parallel to the worldwide decline in fertility, marked mortality improvements have been achieved in most of the world. Approximately half of the world's population succeeded in meeting the International Conference on Population and Development (ICPD) Program of Action goal of reaching a higher-than-seventy-years life expectancy at birth for both sexes from 2000 to 2005. In many industrialized nations, life expectancy at birth is rapidly approaching eighty years. East Asia, Hong Kong, Macao, and Japan have already surpassed the eighty-year level. 
As a result of these rapid fertility and mortality transformations, population age distributions are being transformed, with a relative increase in the numbers of elderly and a relative decrease in the numbers of young. Thus, the twenty-first century is likely to become the century of population aging (Lutz, Sanderson, and Scherbov 2004).

In many countries, both developed and developing, the age structure shifts are generating a wide range of disruptions at both societal and familial levels. At the societal level, many governments, mainly in developed regions, are concerned about adverse effects of population aging on various socioeconomic dimensions, ranging from their national productivity, labor supply and its quality, savings and capital formation, to the financial sustainability of their pension schemes and health care programs. At the familial level, couples are having fewer children later in their lives. Marriage is delayed, more may never marry, and divorce is on the rise. More people are living alone, and more elderly couples are living independently from their children. These family-level demographic developments are affecting the ways in which family members interact with each other, especially in providing support to their elderly parents and children (Ermisch 2003).

By and large, these general observations apply to contemporary Japan. Its postwar fertility decline was the earliest to occur in the nonWestern world, and was also the most rapid among all industrialized nations. Japan's longevity is currently at the highest level in the contemporary world. As a consequence, Japan's population has been aging extremely fast over the past several decades, and its proportion aged sixty-five and over is currently the highest in the world. Japan's social structure and family organization differ substantially from those in developed nations in the West (Hodge and Ogawa 1991; Ogawa and Retherford 1993, 1997; MacKellar 2003; Ogawa, Retherford, and Matsukura 2009). For these reasons, Japan has already faced, and most likely will continue to encounter a variety of problems, both serious and unique, as it adjusts to population aging and adjusts resources allocated to a rapidly growing elderly population.

After reviewing some key features of Japan's demographic dynamics during the postwar period, we discuss the impact of population aging on both public and familial intergenerational transfers in Japan during the last few decades. We then describe some vital features of Japan's socioeconomic system that have been affected by rapid population aging with important implications for the welfare of the elderly over the foreseeable future. Japan's ability to cope with population aging will be governed by public and familial systems of intergenerational transfers. We will rely on new estimates for Japan from 1984 to 2004, generated as part of an international project called National Transfer Accounts (NTA). In the final section, we consider some policy options available to twenty-first-century Japan for coping with its unprecedented population aging.

We confine the scope of this chapter specifically to the Japanese context. However, Japan's experiences in population aging and its policy development 
may provide a useful base for analyzing important policy issues related to population aging in a number of developing countries, particularly those in Asia, which are currently undergoing rapid age structural transformations. Moreover, in the face of its fast postwar economic development, Japan still retains some of its traditional cultural values, which is why the Japanese model may be of relevance to policy makers in the developing regions who are interested in establishing a comprehensive approach by combining the best of traditional and modern values in providing care and support to the elderly.

\subsection{Rapid Demographic Transition in Postwar Japan}

\subsubsection{Falling Fertility and Mortality}

Japan's fertility transition began in the early part of the twentieth century with gradual fertility reduction (Hodge and Ogawa 1991). After World War II, however, the tempo of the reduction became extremely rapid. Following a short baby boom period (1947 to 1949), Japan's TFR declined by more than 50 percent from 4.54 to 2.04 children per woman between 1947 and 1957. This 50 percent reduction of fertility over the ten-year period is the first such experience in documented history.

Thereafter, there were only minor fluctuations around the replacement level until the first oil crisis occurred in 1973, triggering a series of restructuring in the Japanese economy, which, in turn, slowed down the pace of Japan's economic growth. Parallel to this, Japan's fertility level started to fall again, as presented in figure 4.2. By the mid-1990s, Japan's TFR declined below 1.5 children per woman. In 2005 it further plummeted to 1.26 , lowest in postwar time, before a rebound to 1.32 in 2006, and 1.34 in 2007. This post-1973 decline is referred to by some demographers as "Japan's second demographic transition" (Ogawa and Retherford 1993; Retherford and Ogawa 2006; Ogawa, Retherford, and Matsukura 2009).

In line with these changes in TFR, the birth cohort size varied considerably over time, as depicted in figure 4.2. During the baby boom period, there were, on average, approximately 2.7 million births per year, but by 1957 , the number of births decreased to 1.6 million. In the early 1970s, however, despite the low fertility rate, the number of births increased to more than 2 million, as an "echo" effect of the baby boom, or the often called "secondgeneration baby boomers." Since then, births have again trended downward, reaching slightly less than 1.1 million in 2007 . This represents a 60 percent decline in the annual number of births from record levels reached in the late 1940s.

Japan's fertility has attracted a great deal of attention both at home and abroad. In contrast, relatively limited attention has been paid to the speed of Japan's postwar mortality transition. From 1950 to 1952, life expectancy at birth was 59.6 years for men and 63.0 years for women. In 2007, male 


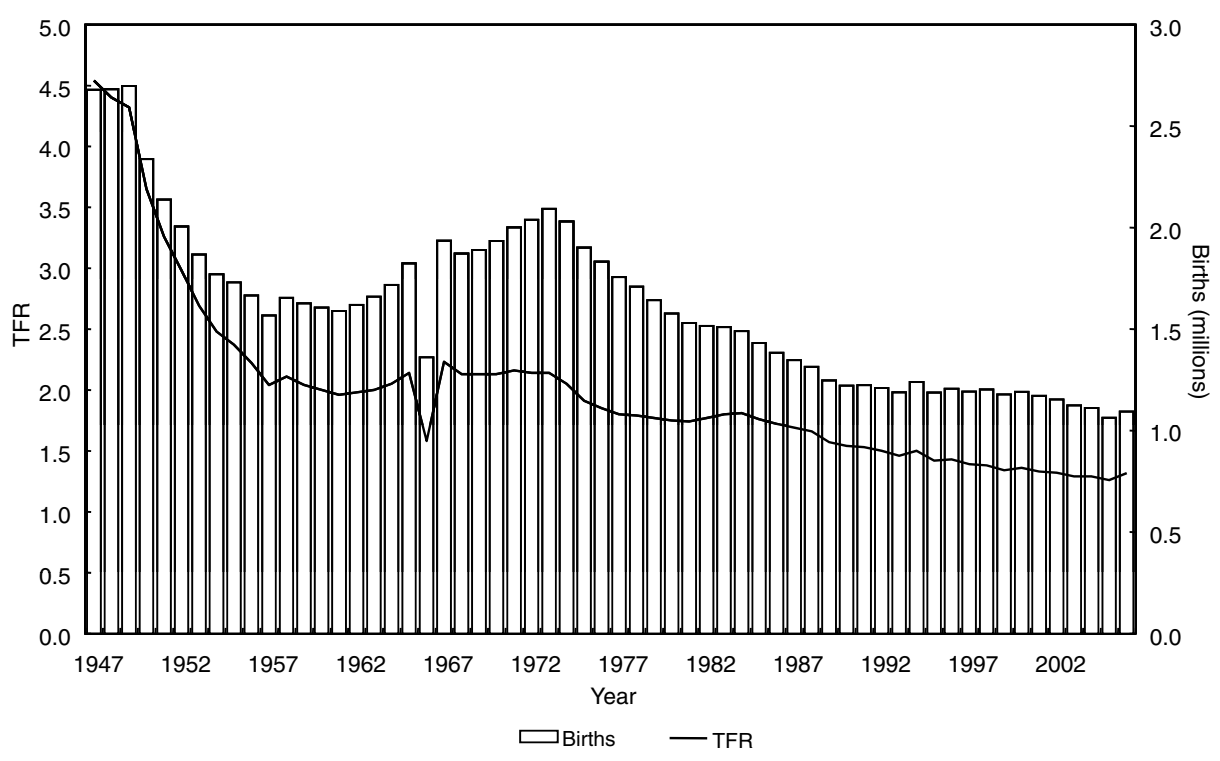

Fig. 4.2 Trends in number of births and TFR: Japan, 1947-2006

Source: Ministry of Health, Labour, and Welfare, Vital Statistics, various years.

life expectancy at birth reached 79.2 years to become the third highest in the world, following Iceland (79.4 years) and Hong Kong (79.3 years), and female life expectancy rose to 86.0 years, the highest in the world, followed by Hong Kong (85.4 years) and France (84.1 years). Moreover, between 1950 and 2007, life expectancy at age sixty-five grew to a substantial extent, from 11.4 to 18.6 years for men, and from 13.4 to 23.6 years for women, which implies a marked increase in the retirement period and in the joint survival to older ages for both husbands and wives.

The remarkable increase in longevity has influenced many aspects of Japan's economy. In 2007, insurance companies reduced premiums substantially for the first time in eleven years (The Asahi Shimbun 2007). The composition of sales by Japanese life insurance companies have shifted in response to longer life expectancy, lower childbearing, and rising divorce. In 2008, for the first time ever, outstanding annuity and medical insurance policies, rather than life insurance contracts, constituted more than half of the products sold by Japanese life insurance companies (The Nikkei 2008a).

A remarkable feature of aging is rapid growth in the number of centenarians. The average annual growth rate, 13 percent over the period from 1963 to 2007 , exceeds that of any other age group in Japan.

In figure 4.3, the data on the average age of the thirty oldest deaths in each year over the period from 1950 to 2006 are plotted separately for men and women. The average age of the thirty oldest deaths increased substantially 


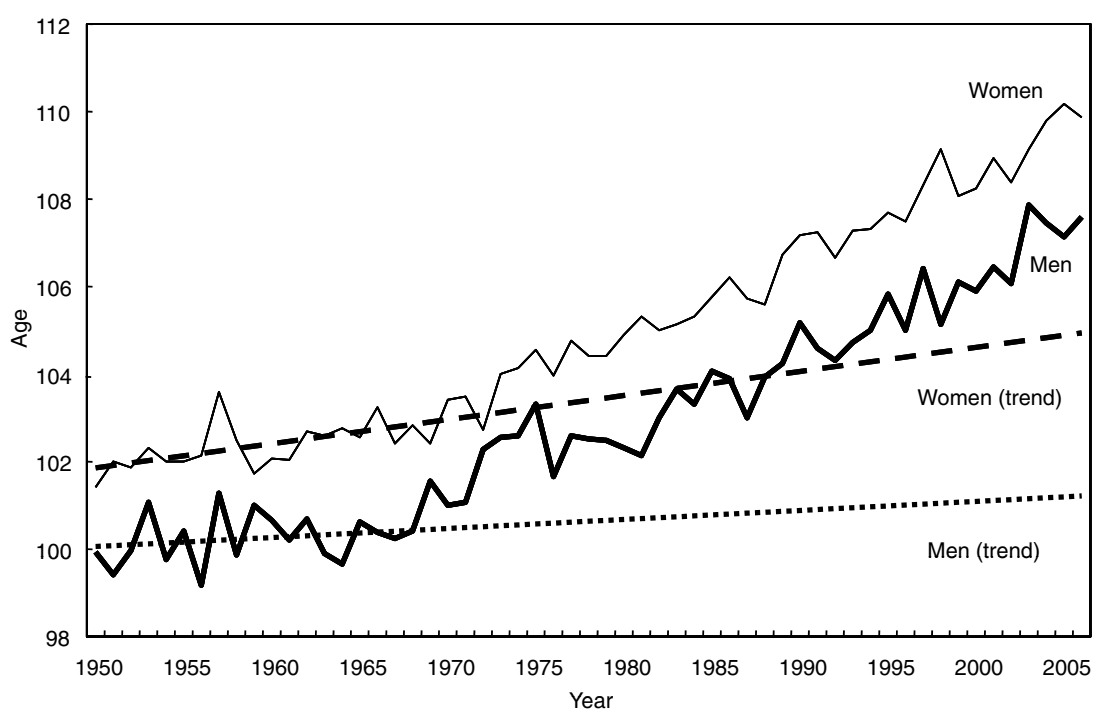

Fig. 4.3 Change in average age of death among thirty oldest persons by sex:

Japan, 1950-2006

Source: Ministry of Health, Labour, and Welfare, Vital Statistics, various years.

Note: The trend lines for men and women have been estimated on the data from 1950 to 1968.

over the second half of the twentieth century for both sexes; in 2006 the average age of the thirty oldest deaths was 107.6 years for men and 109.9 years for women. More importantly, the plotted trends of the thirty oldest deaths indicate that the tempo of life prolongation accelerated for both sexes since the mid-1960s, a few years after the implementation of universal health coverage.

\subsubsection{Population Decline and Aging}

Although the number of elderly in Japan has been increasing rapidly, the number of children, those under age fifteen, has been declining for twentyseven consecutive years; Japan now has fewer children than at any time since 1908 (Washington Post 2008). The overall size of Japan's population began declining from the end of 2005 . According to a population projection based on the most recent version of the population-economic-social security model constructed by the Nihon University Population Research Institute (Ogawa et al. 2003), the total population is expected to decrease to 121.1 million persons in 2025, a 5.2 percent reduction from 2005.

Changes in age structure and other important demographic data are reported in table 4.1. The proportion of the population aged sixty-five and older increased from 4.9 percent in 1950 to 20.2 percent in 2005, and is projected to increase to 31.0 percent in 2025 . Japan's population will likely con- 
Table 4.1

Population change in Japan: 1950-2025

\begin{tabular}{|c|c|c|c|c|c|c|c|}
\hline Year & $\begin{array}{c}\text { Total } \\
\text { population } \\
(1,000 \text { persons })\end{array}$ & $\begin{array}{c}0-14 \\
(\%)\end{array}$ & $\begin{array}{l}65+ \\
(\%)\end{array}$ & $\begin{array}{l}\text { Total } \\
\text { fertility } \\
\text { rate }\end{array}$ & $\begin{array}{c}\text { Total } \\
\text { dependency } \\
\text { ratio }\end{array}$ & $\begin{array}{c}75+/ 65+ \\
(\%)\end{array}$ & $\begin{array}{c}\text { Women } \\
40-59 / 65-84\end{array}$ \\
\hline 1950 & 83,200 & 35.4 & 4.9 & 3.65 & 67.5 & 25.7 & 1.82 \\
\hline 1955 & 89,276 & 33.4 & 5.3 & 2.37 & 63.1 & 29.2 & 1.81 \\
\hline 1960 & 93,419 & 33.0 & 5.7 & 2.00 & 60.4 & 30.4 & 1.80 \\
\hline 1965 & 98,275 & 25.6 & 6.3 & 2.14 & 46.8 & 30.3 & 1.77 \\
\hline 1970 & 103,720 & 23.9 & 7.1 & 2.13 & 44.9 & 30.2 & 1.69 \\
\hline 1975 & 111,940 & 24.3 & 7.9 & 1.91 & 47.6 & 32.0 & 1.60 \\
\hline 1980 & 117,060 & 23.5 & 9.1 & 1.75 & 48.4 & 34.4 & 1.48 \\
\hline 1985 & 121,049 & 21.5 & 10.3 & 1.76 & 46.7 & 37.8 & 1.40 \\
\hline 1990 & 123,611 & 18.2 & 12.1 & 1.54 & 43.5 & 40.1 & 1.30 \\
\hline 1995 & 125,570 & 16.0 & 14.6 & 1.42 & 50.4 & 39.3 & 1.10 \\
\hline 2000 & 126,926 & 14.6 & 17.4 & 1.36 & 46.9 & 40.9 & 0.91 \\
\hline 2005 & 127,449 & 13.8 & 20.2 & 1.25 & 50.6 & 45.1 & 0.77 \\
\hline 2010 & 127,013 & 13.0 & 23.0 & 1.24 & 55.6 & 48.0 & 0.65 \\
\hline 2015 & 125,603 & 12.1 & 26.9 & 1.24 & 63.2 & 48.4 & 0.59 \\
\hline 2020 & 123,235 & 11.0 & 29.5 & 1.24 & 67.6 & 52.1 & 0.57 \\
\hline 2025 & 120,094 & 10.2 & 31.0 & 1.28 & 70.0 & 60.0 & 0.56 \\
\hline
\end{tabular}

Sources: Statistics Bureau, Population Census, various years. Nihon University Population Research Institute, Population Projection, 2003.

tinue to be the world's oldest national population for the next twenty years. More importantly, the Japanese population will reach the world's highest level of aging at an unprecedented rate, as discussed elsewhere (Ogawa and Retherford 1997; Ogawa et al. 2003). Compared with such European countries as Sweden and Norway, the tempo of aging in Japan is approximately three times as fast. Furthermore, the percentage of the population aged seventy-five and older among those aged sixty-five and older is projected to increase from 45.1 percent in 2005 to 60.0 percent in 2025. Comparing NUPRI projections and recent United Nations (2007) projections reveals that Japan's concentration in the seventy-five and older age group is likely to be by far the highest in the world in 2025, followed by Sweden (52.1 percent) and Italy (51.8 percent).

\subsection{Changing Economic Growth Performance and Public Transfer Programs}

\subsubsection{Macroeconomic Growth}

During World War II, Japan's productive capacity was utterly shattered. In 1959, Japan's per capita gross national product (GNP) was only U.S. \$153, lower than that of Mexico (U.S. \$181) or the Philippines (U.S. \$172). By the end of the 1950s, however, Japan's real per capita income had recovered to 
prewar levels. During the 1960s, Japan's real GDP grew at a phenomenal rate of about 11 percent per annum. After the oil crisis of 1973, as mentioned earlier, Japan's economic growth performance became significantly less impressive. In the mid-1980s, the Japanese economy entered the bubble economy phase. Its investment boom ended abruptly in the second half of 1990 and a number of leading banks and other financial institutions became insolvent. Government debt has been accumulating at an alarming rate, reaching U.S. $\$ 8.49$ trillion in 2008. Debt has more than doubled during the last ten years, and its relative size to GDP is by far the worst among industrialized nations. Japan's international competitiveness has deteriorated very quickly. In the early 1990s its economy ranked first in terms of international competitiveness, but it fell to the twenty-second place in 2008 (IMD 2008). In view of these prolonged economic problems, some economists call the 1990s "Japan's lost decade" (Yoshikawa 2001).

Japan has undertaken many important structural reforms of its economy, but its mandatory retirement policy still remains an extreme case as compared with other industrialized nations (Clark et al. 2008). The proportion of firms having mandatory retirement rules has been increasing, not decreasing. The Japanese government is currently attempting to encourage firms to increase the mandatory retirement age to sixty-five. The Law Concerning Stabilization of Employment of Older Persons, passed in 2004, requires firms to increase the age of mandatory retirement to sixty-five. However, no penalties are imposed for noncompliance (Japan Institute of Labour Policy and Training 2004).

Despite these mandatory retirement policies, the elderly have high labor participation rates by international standards (Ogawa, Lee, and Matsukura 2005; Matsukura, Ogawa, and Clark 2007). In 2000, the labor force participation rate for elderly Japanese men aged sixty-five and over was greater than 30 percent. In sharp contrast, the corresponding figure for developed countries in Europe was below 10 percent, and was 18 percent for the United States. Similarly, Japanese women are more likely to continue working than older women in Europe and the United States.

\subsubsection{Old-Age Pension and Medical Care Plans}

As Japan recovered from the shambles of World War II, it established universal pension and medical care schemes in 1961. Since then, Japan's social security system has grown remarkably. Between 1961 and 2005, the share of social security benefits increased from 4.9 to 23.9 percent of the national income (National Institute of Population and Social Security Research 2007). Moreover, the proportion of the social security expenditure allotted to the pension schemes increased from 22.7 percent in 1964 to 52.7 percent in 2005, while the corresponding value for the medical schemes declined from 54.4 to 32.0 percent. Owing to population aging, as well as the maturity of the old-age pension schemes, the relative share of pension benefits paid out in national income has been on an upward trend in recent years. 
Japan undertook major reforms of its public pension schemes in 2004. One of the primary objectives was to fix the level of future contributions for younger workers and thereby increase transparency, without reducing the benefits considerably. The government introduced a mechanism to automatically balance benefit levels according to future changes in the population age structure. The goal was to avoid repeated reforms and to restore the younger generations' trust in government pension schemes. This may be regarded as a paradigm shift in Japan's social security provisions (Sakamoto 2005). As a consequence of the 2004 reform, the replacement rate for the Japanese public pension declined considerably, and is projected to fall to 50.2 percent by 2023 , after which, it is assumed, will remain unchanged up to 2050.

Such downward adjustments of benefits have been clearly reflected in the expectations of the Japanese. According to a national survey on the economic life of the elderly undertaken by the Cabinet Office during January to February, 2007 (The Nikkei 2008b), 56.9 percent of respondents aged fifty-five and over (including baby boomers nearing the mandatory retirement age) stated that their pension benefits would fall short of their living expenses from age sixty. In the 2002 round of this survey, the proportion of those who held this pessimistic view was 46.6 percent.

The second major component of social security benefits is medical. Subject to Japan's economic growth performance, the coverage in medical insurance plans has been revised on a periodic basis. Despite the changes that have taken place in the past few decades, the absolute amount of financial resources allotted to medical care services has been rising. One of the problems that have set Japan apart from other industrialized nations is an extremely long period of hospitalization (Ogawa et al. 2007). In 2005 it was 35.7 days, which is the longest among the nineteen Organization for Economic Cooperation and Development (OECD) countries, followed by 13.4 days in France (OECD 2007).

In response to the upward spiral in medical care costs, the government of Japan implemented the Long-Term Care Insurance (LTCI) scheme in 2000 with a view to reducing the average duration of hospitalization for inpatient care by facilitating in-home care. The LTCI scheme was expected to alleviate the care-giving burden to be placed upon family members, many of whom are middle-aged women (Ogawa and Retherford 1997). Because the expenditure for the LTCI scheme had grown at an alarming rate since its inception, the scope of its services was critically reviewed and downgraded in 2006 with a view to curbing future costs.

In April 2008, the government implemented a new medical insurance scheme specifically for senior citizens aged seventy-five and older as another step toward curbing the nation's mushrooming medical costs. Under this new medical scheme, premiums are automatically deducted from pension payouts. However, because premiums have actually become higher under the new scheme for a certain segment of the targeted elderly age group, a 
possible revision of the new scheme has already become an urgent political issue.

\subsection{Weakening Familial Support and Abrupt Normative Shifts}

As distinct from developed countries in the West, multigenerational living arrangements are still fairly common in Japan (Ogawa and Ermisch 1996; Ogawa, Retherford, and Matsukura 2009). Although three-generational households persist in Japan, the proportion of elderly living with adult children is declining and with it the potential for family support for the elderly. As shown in figure 4.4, the proportion of those aged sixty-five and over coresiding with their adult children declined from 70 percent in 1980 to 43 percent in 2005. In addition, the index called the familial support ratio (expressed as the ratio of women aged forty to fifty-nine to elderly persons aged sixty-five to seventy-nine) is expected to decline substantially over the next twenty years. The value of this index was 1.30 in 1990, and is projected to be 0.65 in 2010 , a 50 percent decline. The present value of this index is the lowest in the entire world and is expected to continue to be so for another twenty years.

Apart from these demographic transformations, value shifts among Japanese people have been dramatic. These value changes are well captured in the data gathered in the National Survey on Family Planning series, conducted

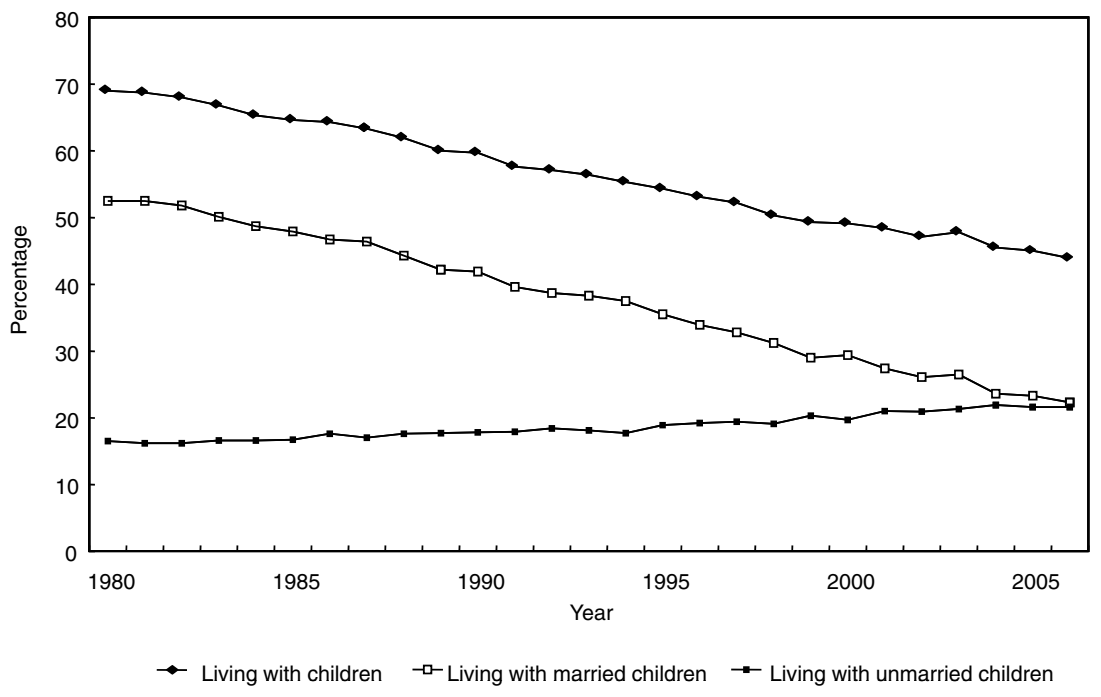

Fig. 4.4 Change in proportion of those aged sixty-five and over coresiding with their adult children: Japan, 1980-2006

Source: Ministry of Health, Labour, and Welfare, Comprehensive Survey of Living Conditions of the People: Health and Welfare, various years. 
every other year from 1950 to 2004 by the Mainichi Newspapers (Population Problems Research Council 2004). Since the first round of the survey, except for a few rounds, a question regarding dependence on children for old-age security had been directed to currently married women of reproductive age who have at least one child. In addition to these time-series data obtained by the Mainichi Newspapers, we have extended the time span, as depicted in figure 4.5, by utilizing data collected in the National Survey on Work and Family, undertaken by the Nihon University Population Research Institute in 2007.

The precoded responses were as follows: (a) "expect to depend on children," (b) "do not expect to depend on children," and (c) "never thought about it." The proportion of respondents who expect to depend on their children declined almost continuously over the period from 1950 to 2004. Almost two-thirds of Japanese married women in 1950 expected to depend on their children for old-age security, but only 9 percent in 2007 expected to do so. These long-term downward trends in parents' expectations for familial support closely parallel the expansion of old-age public pensions since the early 1960s.

In the National Survey conducted by the Mainichi Newspapers since 1963, the question on the attitude of married women towards taking care of their aged parents was asked in successive rounds. The precoded response cat-

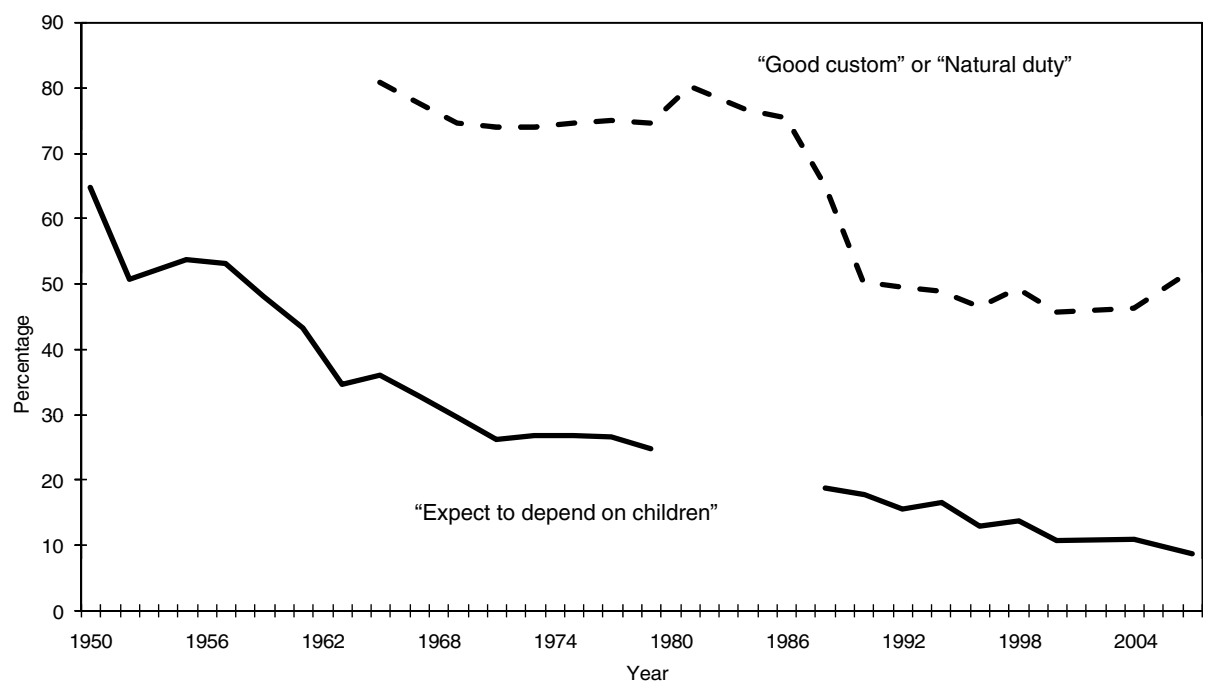

Fig. 4.5 Trends in values and expectations about care for the elderly: Japan, 1950-2007

Sources: Mainichi Newspapers of Japan, Summary of Twenty-fifth National Survey on Family Planning, 2005. Mainichi Newspapers of Japan, Summary of the 2004 round of the National Survey on Population, Families and Generations, 2004. Nihon University Population Research Institute, National Survey on Work and Family, 2007. 
egories are as follows: (a) "good custom," (b) "natural duty as children," (c) "unavoidable due to inadequacy of public support resources," and (d) "not a good custom." We have also supplemented these time-series data compiled by the Mainichi Newspapers with the data gathered by Nihon University. As indicated in figure 4.5, the proportion of those who chose one of the first two response categories ("good custom" and "natural duty as children") was stable from 1963 to 1986. From 1986 to 1988, however, a sudden decline occurred. In the years leading up to 2007, the proportion of married women of reproductive age who chose one of these two response categories was, by and large, declining.

Obviously, these demographic and socioeconomic transformations in postwar Japan have been affecting the pattern and mode of intergenerational transfers over time. To analyze these changes in intergenerational transfers, we will draw heavily upon some of the principal findings recently generated from the National Transfer Account (NTA) project for Japan. A detailed explanation of NTA's basic concept, the crucial computational assumptions used, and the definitions of key variables are available on the NTA home page (http://www.ntaccounts.org).

\subsection{Population Aging, Intergenerational Transfers, and Two Demographic Dividends}

The economic life cycle is fundamental to understanding the macroeconomic effects of population aging. As has been recently discussed elsewhere (Bloom and Williamson 1998; Mason 2001, 2007; Mason and Lee 2006, 2007), the divergence between production and consumption interacts with changing population age structure to generate a demographic dividend, which has been substantial but transitory in Asia. Mason and Lee have shown that a second and sustainable dividend is possible due to increased accumulation of physical or human capital (Lee and Mason 2009; Mason 2007; Mason and Lee 2007). One of the key components of the NTA system is detailed information pertaining to the life cycle of production (labor income) and consumption. This information can be used to calculate the economic support ratio and quantify the extent to which per capita income has been influenced by changes in the working share of the population; that is, the first demographic dividend. The economic life cycle also provides key information for modeling the second demographic dividend, as explained below.

Fertility decline leads to the first demographic dividend because the population in the working ages increases relative to nonworking ages. This is incomplete, however, because gains depend both on what is produced at each age and what is consumed. The first demographic dividend arises because the population is concentrated in ages during which production exceeds consumption. Measuring the dividend in growth terms, the first demographic 


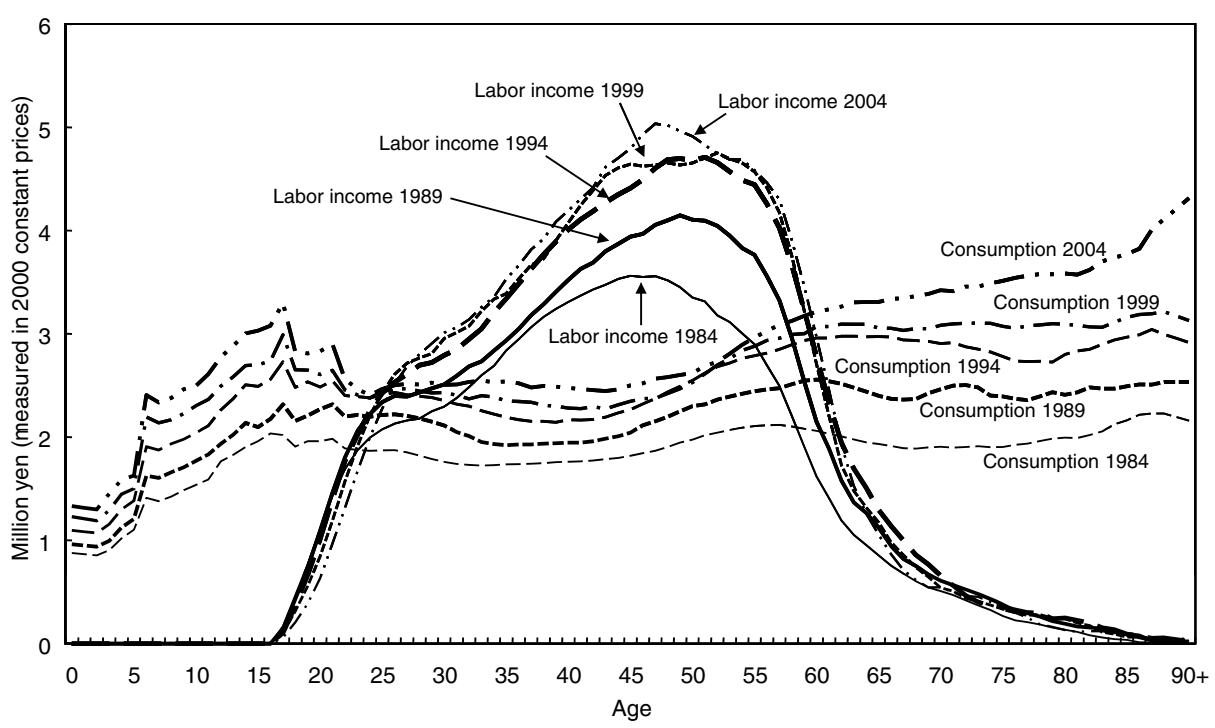

Fig. 4.6 Age-specific profiles of per capita consumption and production: Japan, 1984-2004

dividend is positive when the growth rate of the number of effective producers exceeds that of the number of effective consumers (Mason 2007).

Figure 4.6 shows estimates of age profiles of per capita consumption, both private and public sectors combined, and per capita production (labor income) in five selected years: 1984, 1989, 1994, 1999, and 2004. These profiles have been estimated by drawing upon private-sector data from five rounds of the National Survey of Family Income and Expenditure (NSFIE) from 1984 to 2004, carried out by the Statistics Bureau of Japan, and publicsector data for the corresponding five years, gleaned from various government publications. The estimates are expressed in terms of 2000 prices using the GDP deflator.

A few points of interest emerge from this graphical exposition. First, as expected, throughout the time periods under review, there are sizeable income-consumption deficits at both young and older life-cycle stages. These life-cycle deficits must be funded with reallocations coming largely from the surplus of income generated at the life cycle surplus stage.

Second, the age at which an average individual shifts from a net consumer to a net producer gradually increased from twenty-four in 1984 and 1989 to twenty-five in 1994, and to twenty-six in 1999 and 2004. A number of factors contributed to the upward trend in the crossing age: (a) earnings profiles, (b) hours worked, (c) women's labor force participation and the availability of child-care and old-age leave schemes, (d) sectoral shifts in the labor force, (e) higher enrolment rates in tertiary education, and (f) a marked increase in 
freeters (those aged fifteen to thirty-four who lack full-time employment or are unemployed) and NEETs (those not currently engaged in employment, education or training).

At the other end of the life cycle, the age transition from a net producer to a net consumer rose marginally from fifty-eight in 1984 and 1989 to fiftynine in 1994, 1999, and 2004. The persistency of the crossing age at the later stage of the life cycle can be traced to Japan's mandatory retirement age of sixty. The length of time in the cross-section when individuals are producing more through their labor than they are consuming ranged from thirty-three to thirty-four years, only two-fifths of the average length of life in present day Japan.

Third, labor income increased substantially between 1984 and 1994 reflecting the substantial economic growth during the "bubble economy" phase. The age profiles of per capita production changed little between 1994 and 2004 reflecting the influence of Japan's "lost decade." The growth in labor income that occurred during the entire twenty-year period is concentrated in the prime working ages. Labor income below age twenty-five or above age sixty-five was essentially constant or declined.

Fourth and more importantly, the age profiles of per capita consumption rose almost continuously, particularly at the younger and older ages. Of particular note is the emergence of an upward sloping consumption curve among those aged sixty-five and over in 2004. This is accounted for by the implementation of the LTCI scheme starting from the year 2000. In-home care for the frail elderly, which had until then been informally provided by their family members, became formalized as a part of the market economy. As a result, Japan's per capita consumption profiles have been increasingly similar to those in Finland, the United States, Sweden, and Costa Rica among the NTA member countries.

How and why the economic life cycle is changing in Japan is an important issue, but the concern here is the effects of age structure given the age patterns of consumption and labor income observed in Japan. This analysis is based on an average of the five sets of profiles shown in figure 4.6. The age-specific values, shown in figure 4.7 , are used as weights to calculate the effective number of producers and the effective number of consumers over the period from 1925 to 2025 . The ratio of producers to consumers is the economic support ratio. The first demographic dividend is defined as the annual growth rate of the economic support ratio, which measures the change in output per effective consumer due solely to changes in age structure (figure 4.8). For thirty-four consecutive years from 1945 to 1979, the effective number of producers grew more rapidly than the effective number of consumers in Japan. The magnitude of the positive first demographic dividend was large, adding just over 1 percent per year to economic growth during the rapid economic growth of the 1960s and the early 1970s. 


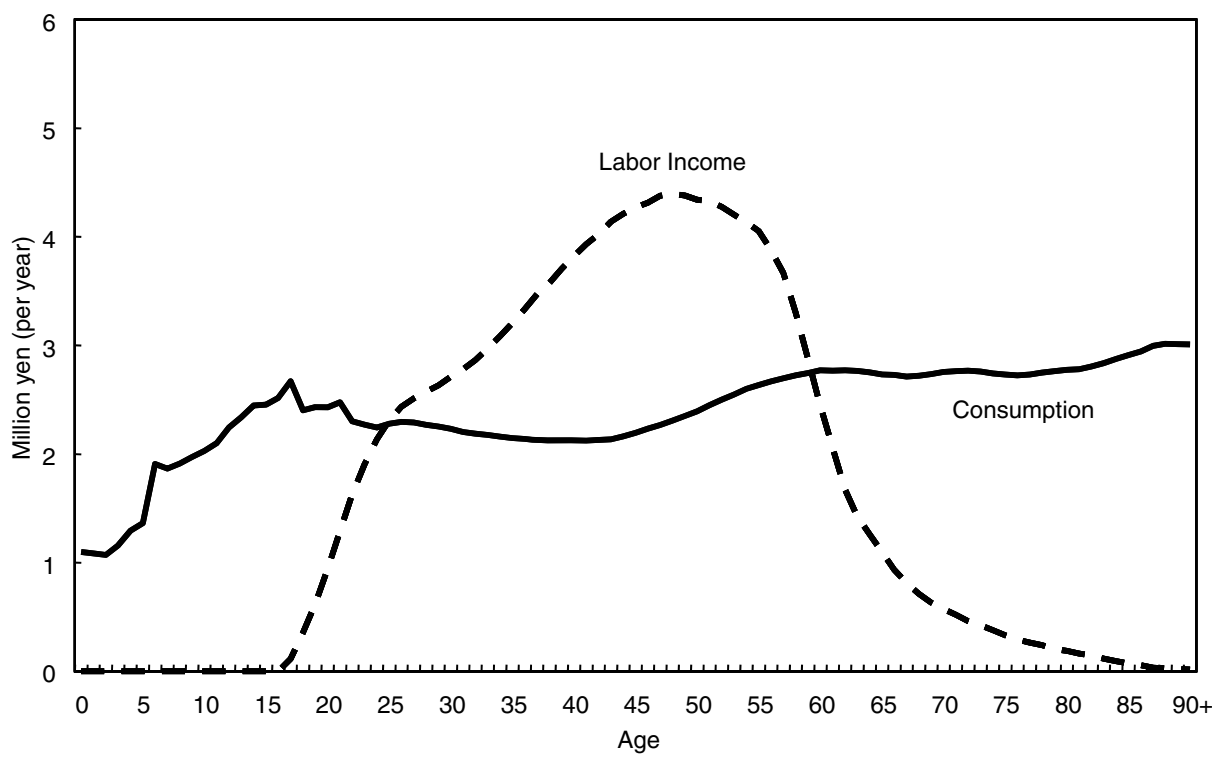

Fig. 4.7 Average age-specific profiles of annual per capita consumption and production: Japan, 1984-2004

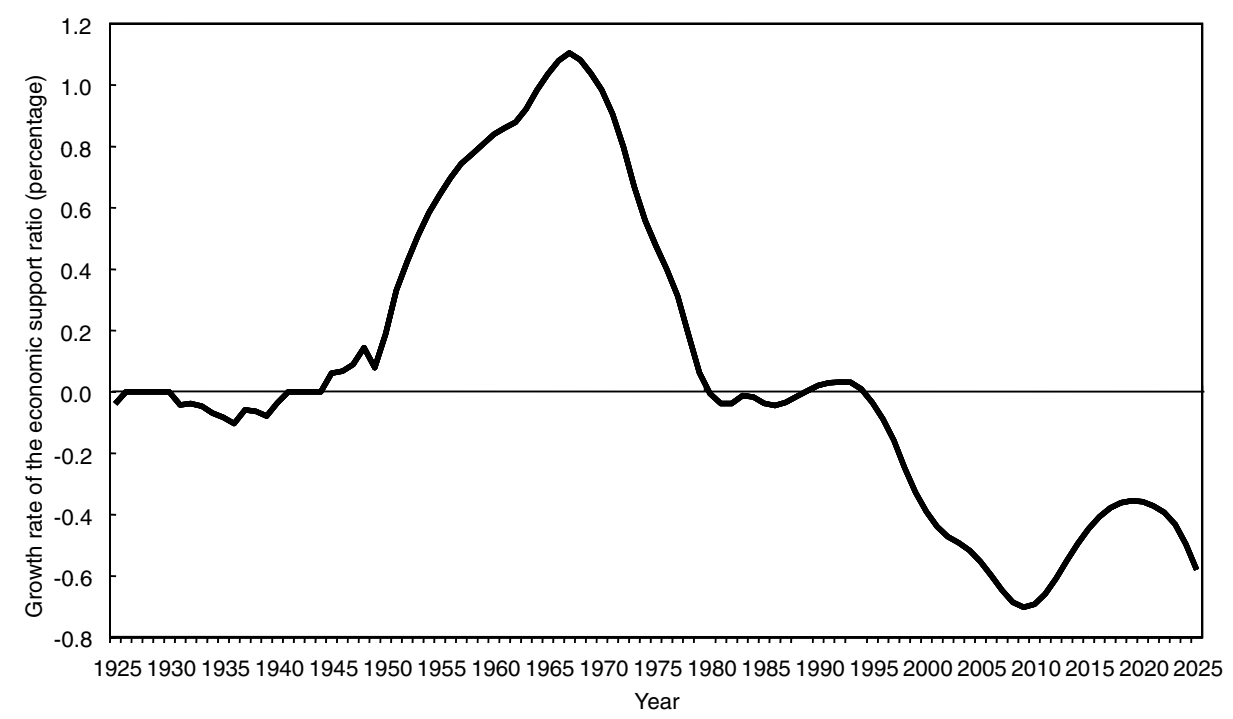

Fig. 4.8 Trend in first demographic dividend: Japan, 1925-2025 
As has been the case with other developed countries, Japan's first demographic dividend lasted for a few decades, but proved inherently transitory in nature. Since the mid-1990s the effective number of producers has been growing more slowly than the effective number of consumers, the economic support ratio has been declining, and the first dividend has turned decidedly negative. This change is a direct consequence of population aging.

The same demographic forces that produce an end to the first dividend may lead to a second demographic dividend. Implicit in the large gap between consumption and production at old ages is the life cycle demand for wealth. To support consumption which in old-age greatly exceeds production, life cycle pension wealth must be accumulated in one of the two following forms. One form is transfer wealth or the net present value of public and private transfers. The second form is assets, which consists of capital, land, foreign assets, and the like. As a population ages, the demand for life-cycle pension wealth increases substantially. In part, this occurs because the duration of retirement is longer due to increased life expectancy and, in part, because of changes in the age composition of the population. If the demand for wealth is met by expanding transfer wealth, then population aging leads to large implicit debts imposed on future generations. If countries rely on capital accumulation to meet the retirement needs of the elderly, population aging provides a powerful incentive to accumulate capital and other assets. A key point is that in countries that rely on transfers, both public and familial, in meeting the retirement needs of the elderly, the second demographic dividend will not emerge. While the first dividend is purely accounting-oriented, the second dividend consists of both compositional and behavioral effects (Mason 2007; Ogawa and Matsukura 2007; Mason and Lee 2007). The second dividend is affected not only by the numbers of the elderly persons relative to younger persons, but also by the extent to which consumers and policy makers are forward-looking and respond effectively to the demographic changes that are anticipated in the years ahead. When life expectancy is increasing, for example, the impetus for accumulating wealth is stimulated, which, in turn, leads to a permanent increase in income. To summarize, if capital accumulation rather than familial or public transfer programs dominate the age reallocation systems for supporting the elderly, population aging may yield a second demographic dividend due to higher rates of saving and capital intensification of the economy.

Compared with the first dividend, measuring the second dividend is difficult, in part because the accumulation of wealth is intrinsically forwardlooking. The demand for wealth depends on expectations about the future that can not be directly measured. In the present study, we have followed a relatively simple partial equilibrium method. As fully discussed elsewhere (Mason 2007), the second dividend is defined as the growth rate of productivity or output per labor income that arises because of an increase in the demand for assets as a consequence of population aging. 
The estimates of the second demographic dividend over the period from 1960 to 2035 are shown in figure 4.9. Japan's second demographic dividend is very high in the 1980s, generating almost 1.5 percentage points of additional economic growth. Beginning from the 1990s, the second demographic dividend fluctuates to a considerable extent, with a trough in the 2010s, followed by a small upsurge in the 2020s. These oscillations occur primarily because the second generation of baby boomers enters the age group of fifty years old and over, in which they are expected to save at a high rate.

Undoubtedly, depending on how the Japanese elderly utilize or allocate their current and future accumulated wealth, the Japanese economy's future scenarios will be substantially different. Numerous banks and life insurance companies are aware of this phenomenon and have recently been paying great attention to the baby boomers born between 1947 and 1949, who are now approaching their mandatory age of retirement. They have already contributed greatly to creating both first and second demographic dividends over the course of Japan's demographic transition after World War II, and they are expected to enjoy the fruits of the second demographic dividend during their retirement life, as hinted in figure 4.9.

Figure 4.10 plots the age profile of asset holding in Japan in 1999 among those aged sixty and over. Using the 1999 round of NSFIE, we have estimated their age-specific stock of real and financial assets. In addition, we have computed the present value of the expected future stream of public pension benefits. The detailed computational procedure and assumptions employed are available elsewhere (Ogawa and Matsukura 2007). A quick glance at this graph reveals that the Japanese elderly are wealthy. At age

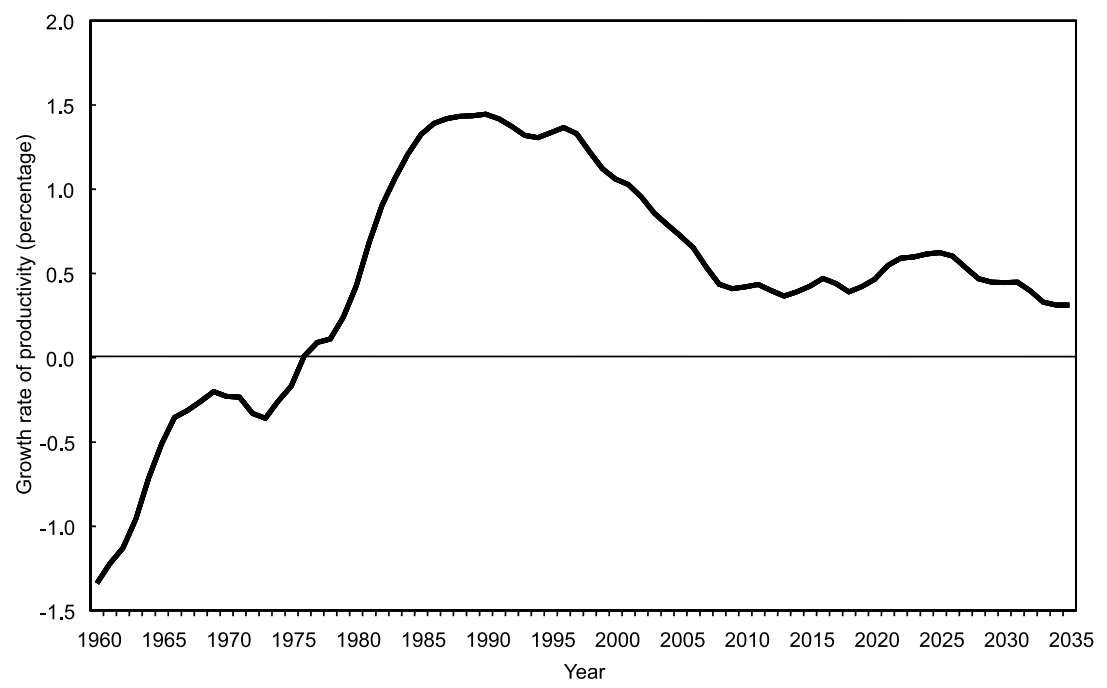

Fig. 4.9 Trend in second demographic dividend: Japan, 1960-2035 


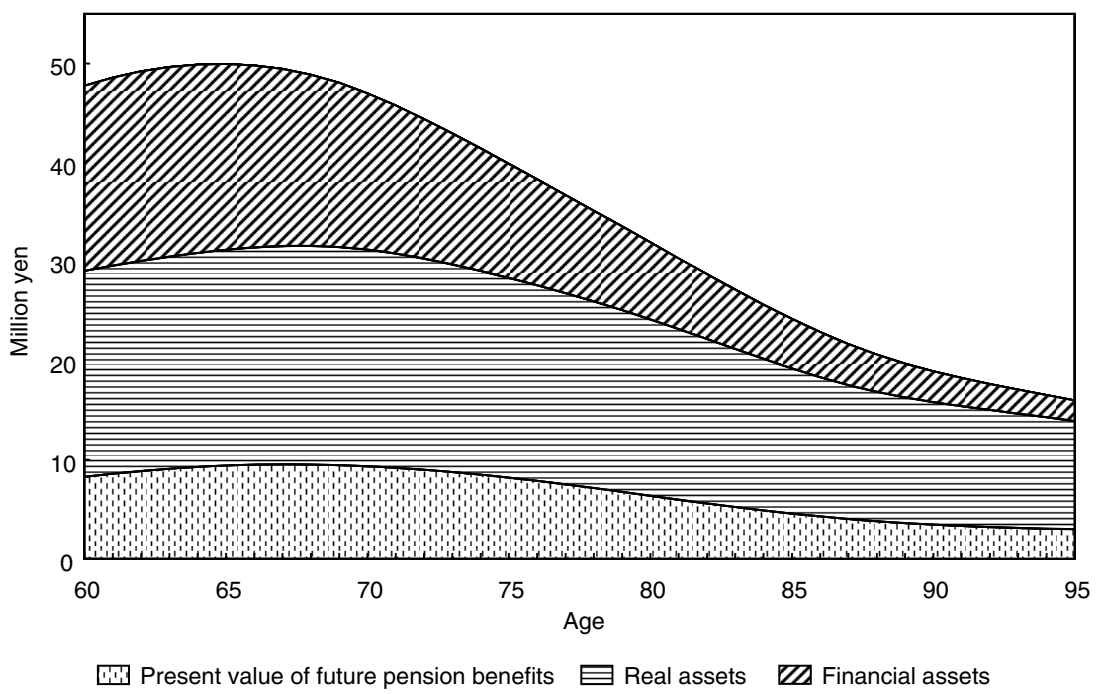

Fig. 4.10 Age profiles of assets and pension wealth transfers in Japan, 1999

sixty, the total amount of assets an average person owns is more than 50 million yen, or U.S. $\$ 0.5$ million. In fact, they are wealthier than what this graph shows, because private pensions are not included in the computation. Also, familial transfers are not included in figure 4.10, but they are discussed below.

A striking feature of the graph is that the present value of public pension benefits to be paid to the elderly is greater than that of real assets at a relatively early stage of retirement life, but the latter exceeds the former by a great margin at a later stage of retirement life. A possible explanation is that the liquidation of real assets such as land and housing is crucial for very old persons, particularly those who are living alone. There seems to be a substantial potential for developing various financial schemes such as the reverse mortgage plan. These are cross-section estimates, however, so that other explanations may be important.

An additional feature of the demand for wealth in Japan is that the preference for land has declined considerably over the last fifteen years or so, during Japan's lost decade. According to various rounds of the National Opinion Survey on Land Issues conducted by the Ministry of the National Land, Infrastructure, Transport and Tourism, the proportion of those aged sixty and over who thought that land was a better asset than financial assets such as savings and securities declined from 63 percent in 1994 to 37 percent in 2007 (figure 4.11). This suggests that an increasing proportion of the Japanese elderly need more information regarding investment opportunities. Caution should be exercised, however, with regard to the lack of 


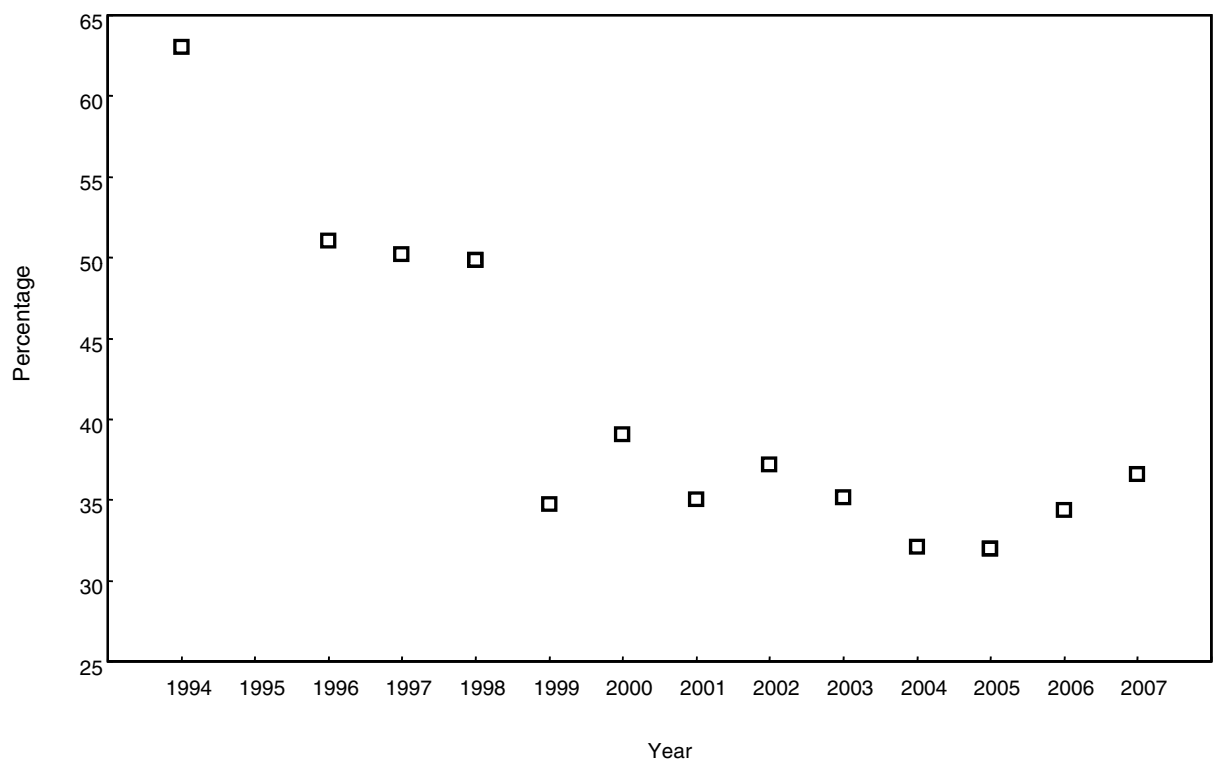

Fig. 4.11 Changing preference for land as an asset among the elderly aged sixty and over: Japan, 1994-2007

Source: Ministry of Land, Infrastructure, Transport, and Tourism, National Opinion Survey on Land Issues, 2007.

appropriate knowledge pertaining to various financial markets. According to a recent report released by the Organization for Economic Cooperation and Development (OECD [2005]), 71 percent of the population aged twenty and over have no knowledge about investment in equities and bonds, 57 percent have no knowledge of financial products in general, and 29 percent have no knowledge about insurance, pensions, and tax. The ongoing global financial crisis will surely influence preferences and knowledge over the coming years.

To cope with these problems, the Financial Services Agency of the Japanese Government implemented the Financial Instruments and Exchange Law, effective from September 30, 2007. This financial business law aims at enhancing investor protection by tightening the rules for financial institutions' sales of stocks, investment trusts, and other products that could cause holders to suffer a loss of principal. As a result, in order to avoid possible regulatory trouble, one of the major banks decided not to sell risk instruments to customers aged eighty and over unless they can demonstrate sufficient knowledge of investing or are accompanied by other family members at the time of purchase (The Nikkei 2007). The large bank requires that customers aged seventy and over receive explanation concerning the risks involved at least twice before they purchase an investment trust or variable annuities. 
Another leading bank has recently begun the practice of visiting customers aged ninety and over once every three months, even if their products do not suffer any losses.

\subsection{Changing Pattern of Life Cycle Deficits and Age Reallocations}

The effect of population aging on the accumulation of assets will depend on the system for reallocating resources across age. The NTA system provides a comprehensive framework for estimating consumption, production, and resource reallocations by age. The NTA measures intergenerational flows for a certain period of time (usually a calendar or fiscal year), and its flow account is governed by the following expression:

$$
\underbrace{Y^{l}(x)+Y^{A}(x)+\tau^{+}(x)}_{\text {Inflows }}=\underbrace{C(x)+S(x)+\tau^{-}(x)}_{\text {Outflows }},
$$

where $Y^{l}=$ labor income, $Y^{A}=$ asset income, $\tau^{+}=$transfers received, $C=$ consumption, $S=$ saving, and $\tau^{-}=$transfers given. It should be noted that this flow identity holds for each age $x$ as well as the whole economy.

Rearranging the terms, the life cycle deficit, namely, the difference between consumption and labor income, $C(x)-Y^{\prime}(x)$, must be equal to the inter-age flows or reallocations that come in the following two forms: net transfers, $\tau(x)=\tau^{+}(x)-\tau^{-}(x)$, and asset-based reallocations, $Y^{A}(x)-S(x)$; thereby giving us the following equation:

$$
\underbrace{C(x)-Y^{l}(x)}_{\text {Lifec cycle deficit }}=\underbrace{\tau^{+}(x)-\tau^{-}(x)}_{\text {Nge reallocations }}+\underbrace{Y^{A}(x)-S(x)}_{\text {Net transfers }} .
$$

The age reallocations can be further disaggregated into public-sector and private-sector age reallocations. That is,

$$
\begin{aligned}
C(x)-Y^{l}(x)= & \left\lfloor\tau_{g}^{+}(x)-\tau_{g}^{-}(x)\right\rfloor+\left\lfloor\tau_{f}^{+}(x)-\tau_{f}^{-}(x)\right\rfloor \\
& +\left\lfloor Y^{A g}(x)-S_{g}(x)\right\rfloor+\left\lfloor Y^{A f}(x)-S_{f}(x)\right\rfloor,
\end{aligned}
$$

where subscripts, $g$ and $f$, refer to public and private age reallocations, respectively.

Before we proceed to the discussion of computational results, we would like to caution the reader about the following two points. First, both "familial transfers" and "private transfers" are used interchangeably in this chapter; both of the terms refer to transfers coming from other family members of the same or different households. Second, the private transfers presented here are limited to current transfers. Capital transfers, for example, bequests and inter vivos capital transfers, are not included.

It is also important to note that the estimated values for the totals are adjusted to match aggregates from National Income and Product Accounts 
(NIPA), thus insuring consistency with NIPA. Labor income, however, does not exactly correspond to the NIPA counterpart, because the income of those self-employed (mixed income) includes returns to labor and capital. Based upon the result derived from one of the recent studies (Gollin 2002), we have opted to allocate two-thirds of this income to labor and one-third to capital.

Figure 4.12 presents the changing pattern of three components of the age reallocations for 1984 to 2004 . The three components consist of reallocations through assets, net public transfers, and net private transfers. All values are measured in terms of 2000 constant prices and on an annual basis. Panel A presents age reallocations for 1984, panel B for 1994, and panel C for 2004.

There are many important changes in age reallocations over this twentyyear period. First, the impact of the rapid growth of the elderly population upon transfers is very clear. Net total transfers to those aged sixty-five and older increased by three times from 1984 to 2004 . The increase is entirely a consequence of net public transfers to the elderly that grew 4.4 times in real terms. In contrast, the amount of net familial transfers to the elderly declines by 75 percent during the same period. Assets have become extremely important for the elderly population - asset-based reallocations increased by ten times in real terms from 1984 to 2004. Despite such phenomenal growth of asset-based reallocations, net public transfers dominated asset-based reallocations for the elderly population in 2004.

Second, despite a large decline in the young population, net transfers to those aged zero to nineteen grew by 9 percent during the two decades. The composition of the net transfers changed appreciably over time. Net public transfers to this age group rose by 35 percent in real terms, while net familial transfers declined by 7 percent.

Third, though relevant tables are omitted, on a per capita basis, net public transfers to both elderly and young persons doubled over the period in question. More importantly, while the amount of net familial transfers to the young population during the two decades rose by 34 percent, there was a 70 percent decline for the elderly population.

Fourth, net public transfers are negative for the productive age groups twenty to fifty-nine with the peak shifting rightward (to higher ages) over time, reflecting the influence of population aging (figure 4.12). In 2004, the peak occurred approximately at age fifty-seven, while in the earlier years the peak occurred between ages forty to fifty. On a per capita basis, however, the peak of the tax burden remained relatively stable in the vicinity of age fifty-five during the period under consideration.

Fifth, the role of asset-based reallocations became increasingly important over time particularly for the elderly, as can be clearly seen from the three panels of figure 4.12. Although asset-based reallocations occur in both private and public sectors, the amount of asset-based reallocations 


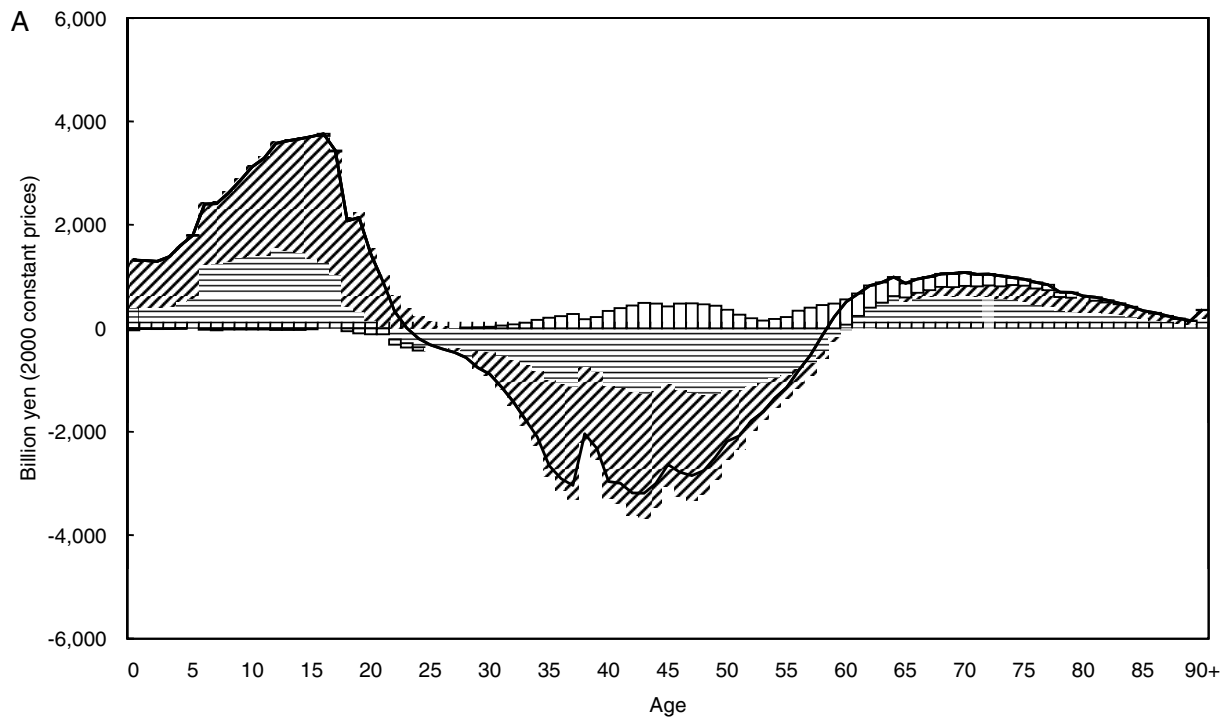

$\Longleftarrow$ Public transfers $\square$ Private transfers $\square$ Asset-based reallocations — Lifecycle deficit

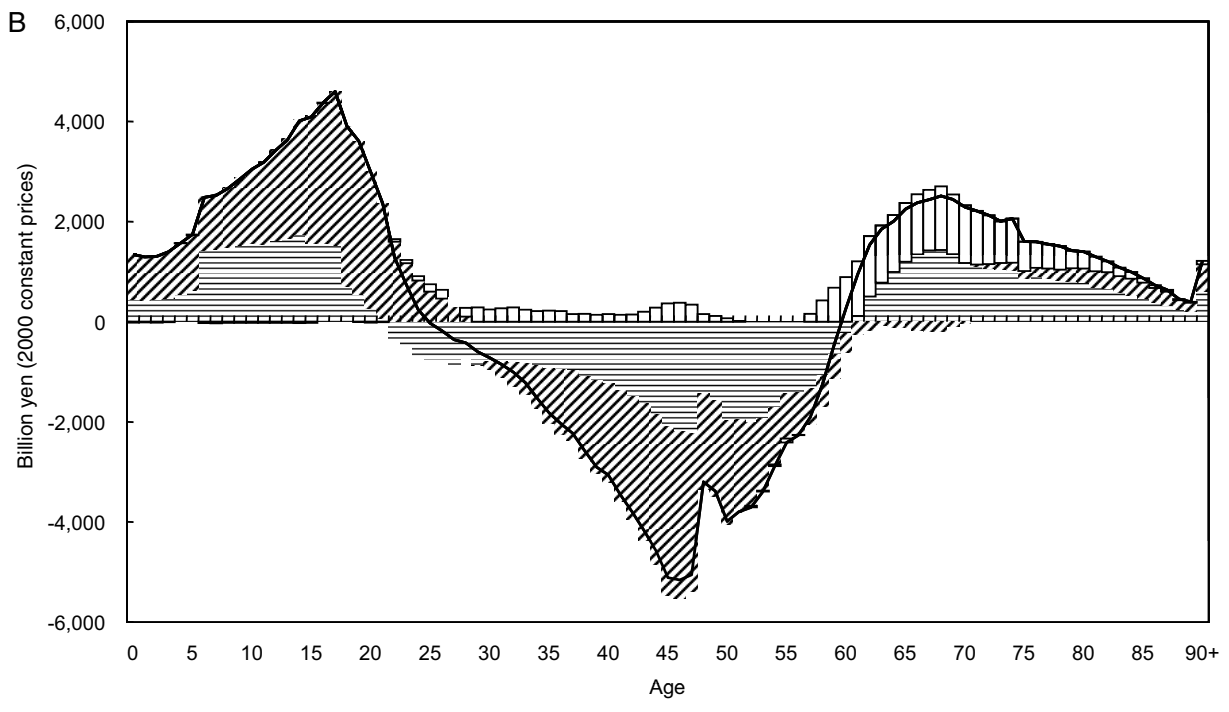

戸Public transfers $\square$ Private transfers $\square$ Asset-based reallocations - Lifecycle deficit

Fig. 4.12 Changing pattern of three components of reallocations: Japan, 19842004: $A, 1984 ; B, 1994 ; C, 2004$.

in the private sector has consistently dominated those in the public sector. Furthermore, a positive asset-based reallocation implies that people receive asset income in excess of their saving. In 2004, for instance, positive assetbased reallocations reach their peak when people are in their sixties, and are comprised largely of the return to private assets (e.g., property income). In 


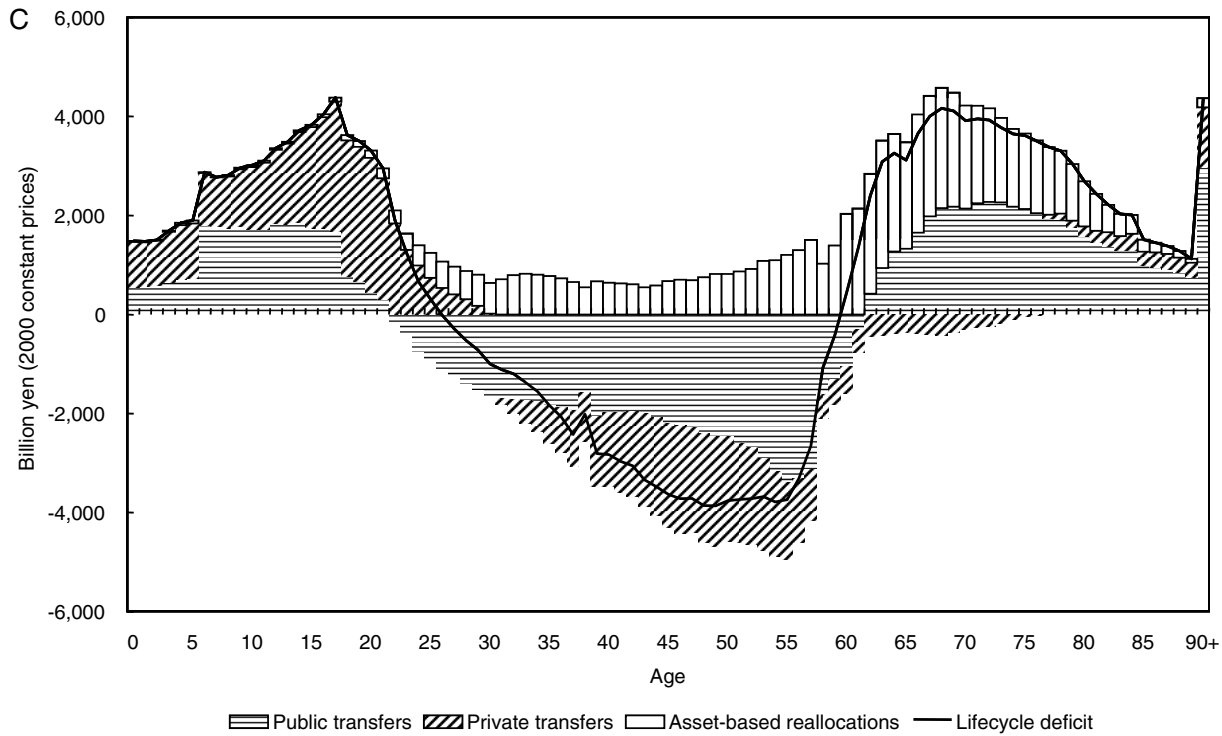

Fig. 4.12 (cont.)

contrast, the small negative asset-based reallocation at young ages in 1984 occurred mainly owing to public saving exceeding public asset income.

Sixth, a careful examination of the three panels reveals that net familial transfers are negative among relatively young elderly persons. This phenomenon is particularly pronounced in 2004 among the elderly in their sixties and seventies (panel $\mathrm{C}$ of figure 4.12). The financial assistance relatively young elderly persons provided to their adult children and/or grandchildren exceeded the monetary assistance the young elderly received. The magnitude of negative net familial transfers for relatively young elderly rose during the period of Japan's lost decade in which the unemployment rate remained at a very high level and labor income hardly grew at all in either nominal or real terms. The data displayed in figure 4.13 further substantiates the validity of this interpretation: all age groups received positive net intra-household transfers from the sixty- to seventy-four-year old age group.

Moreover, according to a nationwide survey undertaken by the Nihon University Population Research Institute in April 2007, the proportion of the survey respondents in their forties who had received financial assistance from their parents over the previous twelve months was approximately 50 percent higher than that of those who had provided financial assistance to their parents. These results suggest that despite the fact that multigenerational coresidence has been eroding over the past few decades, the Japanese elderly are still playing a vital role in providing financial support for their offspring when the latter encounter economic difficulties. Although older persons in Japan are often considered a liability for the country, they are 


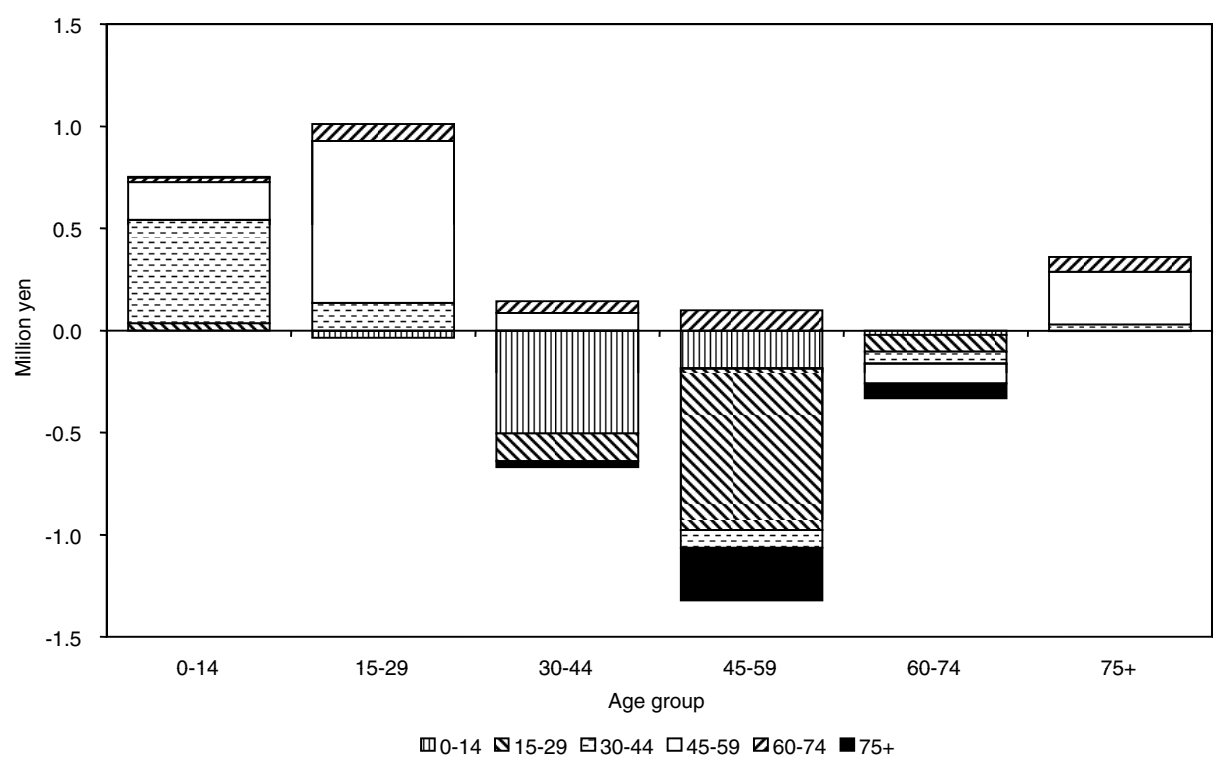

Fig. 4.13 Net per capita annual intra-household transfers between broad age groups: Japan, 2004

actually playing a key role as a safety net. For this reason, they should be considered latent assets in contemporary Japanese society. Ironically, filial norms among the middle-aged have been deteriorating since the late 1980s as displayed in figure 4.5 , and this could be interpreted as partial evidence that elderly parents, despite such deterioration, still, to a considerable extent, remain altruistic toward their children and grandchildren.

Further to our discussion with regard to figure 4.13, we have also plotted net familial transfers to the elderly by age and year in figure 4.14 . The data show an upward shift of the age at which net familial transfers to the elderly become positive. Over the period of two decades, that age rose from sixty-three years old in 1984 to sixty-four years old in 1989, seventy-one years old in 1994, seventy-four years old in 1999, and seventy-seven years old in 2004. These upward shifts over time seem to be closely related to the improved pension benefits due to the maturity of the pension schemes, but causality is difficult to infer here. It is also interesting to observe in figure 4.14 that for any given cohort, the importance of familial transfers does not increase much as the cohort members age. The ratio of net familial transfers to life cycle deficits for the elderly who turned sixty-five in 1984 remained virtually unchanged, around 0.15 , over the subsequent fifteen years, until they reached age eighty in 1999. Similar observations are applicable to those who were seventy and seventy-five in 1984. These plotted results indicate that, from a cohort perspective, there is virtually no age gradient. This seems 


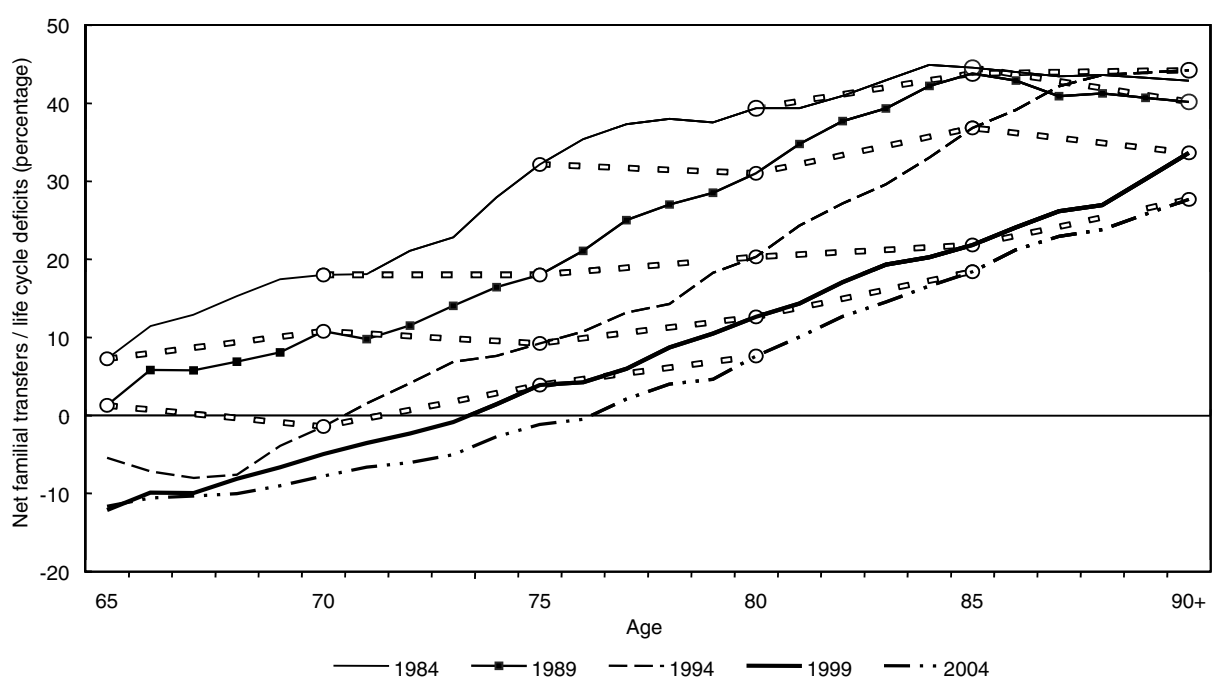

Fig. 4.14 Net familial transfers to the elderly aged sixty-five and older: Japan, 1984-2004

to be accounted for by the intercohort differentials in old-age pension maturity levels, which are heavily affected by the age of each cohort at which the universal coverage of public pension schemes was implemented.

In figure 4.15 , we have plotted the change in the pattern of funding consumption among the two elderly groups (sixty-five and older, and eightyfive and older) from 1984 to 2004. Among those aged sixty-five and over, the role of public pensions was becoming increasingly important. In contrast, as has been already mentioned, familial transfers were becoming less important over time. Surprisingly, in 2004, the share of net familial transfers in funding consumption among the elderly aged sixty-five and over virtually disappeared, although a substantial proportion of the elderly in this age group were still coresiding with their adult children. It should be emphasized, however, that the inflow of familial transfers from the younger population is still significant among those aged eighty-five and over. This may be largely due to the fact that the elderly of this old age group receive a relatively limited amount of pension benefits as a result of (a) their shorter contribution period and (b) the dominance of women receiving a survivor's pension in this very old age group.

Moreover, the data plotted in figure 4.15 indicate the share of asset-based reallocations has been growing substantially over time, particularly among the relatively young elderly, which is consistent with our earlier discussion in connection with figure 4.10. In the case of those aged sixty-five and over, the proportion of consumption funded by asset-based reallocations grew from 14 percent in 1984 to 36 percent in 2004. 


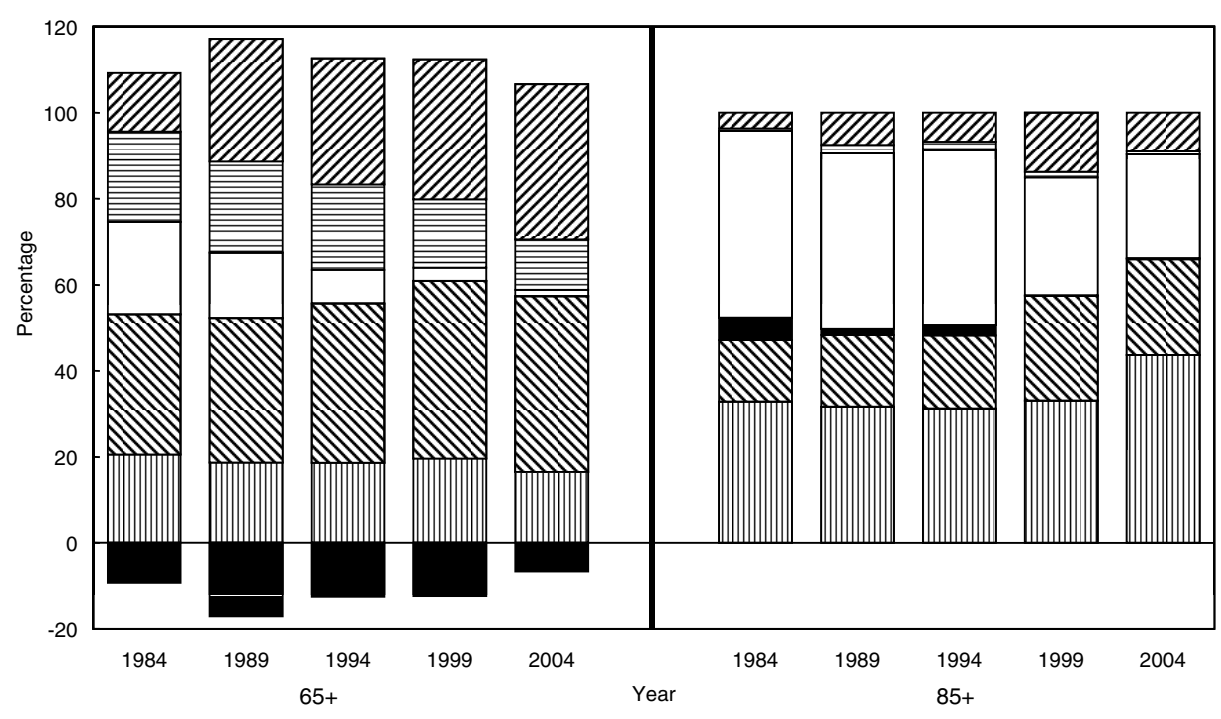

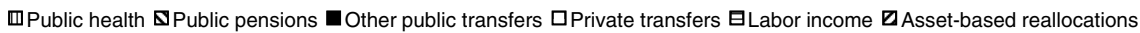

Fig. 4.15 Change in the pattern of financing consumption among the two elderly groups: Japan, 1984-2004

It is also worth remarking that the share of public transfers in the form of medical care services rose to a considerable extent, especially between 1999 and 2004, which is in agreement with our earlier discussion concerning the rise of per capita consumption among the elderly depicted in figure 4.6. It is also interesting to observe in figure 4.15 that, although declining over time, the share of labor income is considerable, which is consistent with the high labor force participation rate among the elderly population in contemporary Japan.

\subsection{Concluding Remarks}

In this chapter, we have analyzed some of the important impacts of Japan's unprecedented population aging on its postwar economy, by drawing heavily upon estimates from the NTA-Japan project, ranging from the first and second demographic dividends to life cycle reallocations. We have also shed light on the rapidly changing roles of public and familial support systems for the elderly in Japan, that have evolved together with the family organizational transformation and the rapid development of the social security system over the past several decades.

As extensively discussed in the literature, Japan's demographic landscape in the twenty-first century is extremely gloomy. In hope of raising marital fertility to alleviate the burden of rapid population aging on the economy, 
the Japanese government has formulated and implemented a series of pronatalist programs and policies since the early 1990s (Ogawa and Retherford 1993; Retherford and Ogawa 2006). And yet, despite such strenuous efforts, the country's fertility remains very low. Judging from the extensive experience of many industrialized countries in the West, there is no apparent panacea for restoring fertility to the replacement level. Moreover, the use of immigration measures is inconceivable in contemporary Japanese society. In view of the results of various recent opinion surveys on the importation of unskilled foreign workers to Japan, it seems safe to say that the introduction of a large-scale immigration policy in Japan is a rather remote possibility. In contrast to this, although the awareness of the two demographic dividends is still fairly limited in Japan, their use, particularly that of the accumulated second demographic dividend which is likely to remain substantial for the next few decades, could be an option for Japan to resume steady economic growth.

One crucial question remains: how can Japanese elderly make use of their accumulated wealth? Depending upon where they invest their financial resources, Japan's future economic growth performance is prone to differ considerably. If Japanese elderly persons are provided with sufficient knowledge about the dynamics of the financial market, they may have a good potential for investing their accumulated assets possibly outside Japan. Moreover, the timing of the first demographic dividend for selected Asian countries varies considerably, as presented in figure 4.16. As examined earlier, Japan's first dividend ended in 1979. In contrast, in the case of China, for instance, the first dividend lasts for forty-one years - from 1973 to 2014.

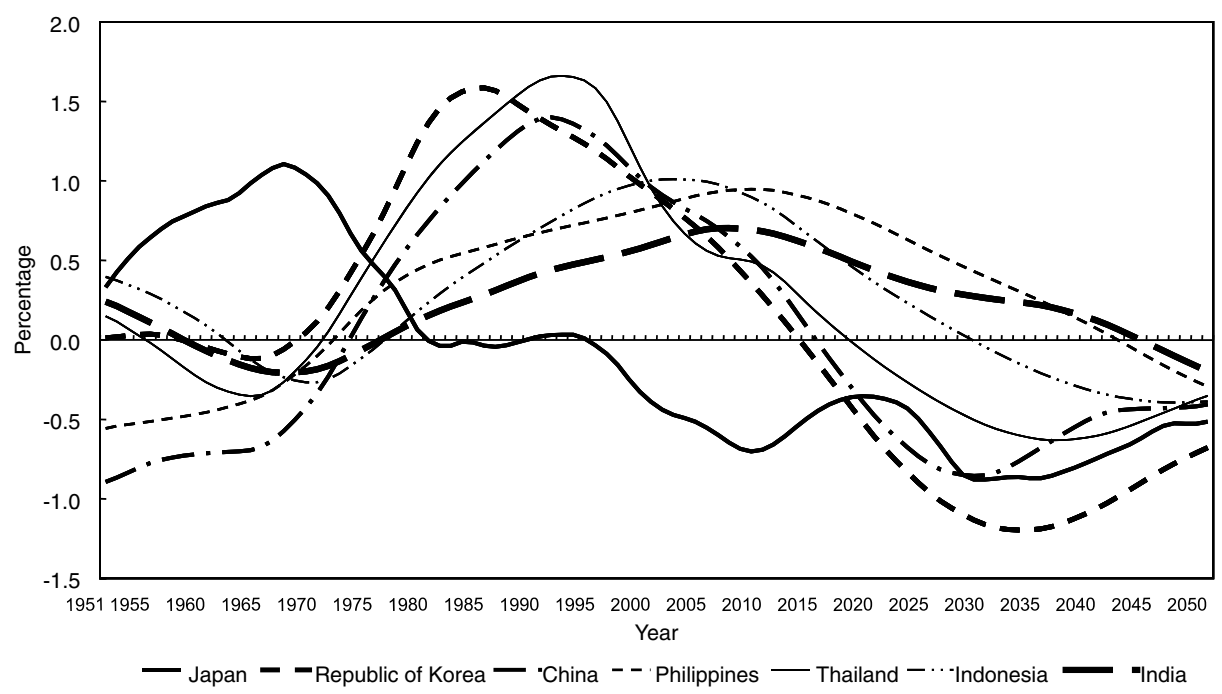

Fig. 4.16 First demographic dividend in selected Asian countries, 1950-2050 
In an era of globalization, the healthier and wealthier among the Japanese elderly will have the opportunity to invest their assets in a dynamically growing Chinese economy, and bring financial gains back to Japan.

In contemporary Japan, the elderly are generally considered to be liabilities. However, the analyses developed in this chapter indicate that the Japanese elderly represent a powerful asset to keep the country on a sound and steady path of growth in the years to come. Furthermore, over the past decade or so, they have been informally playing the role of the society's safety net by providing financial assistance to their adult children and grandchildren suffering from financial difficulties.

In addition, as discussed elsewhere (Ogawa and Matsukura 2007), the number of healthy elderly persons in Japan is expected to increase significantly in the years ahead, and their educational attainment will be higher than that of the elderly in the past. In other words, Japan's future elderly will possess a substantial proportion of both the country's human and financial resources.

Before closing this chapter, it seems appropriate to offer a few words of caution concerning the interpretation of some of the numerical results computed from the NTA-Japan project. First, as pointed out earlier, bequests and other capital transfers are an important flow not included in the present paper. Estimating these flows is a difficult task but one that we hope to address in future work.

Second, although private-sector information derived from the five rounds of the National Survey of Family Income and Expenditure (NSFIE) from 1984 to 2004 is one of the most vital inputs in the NTA-Japan project, the data derived from the NSFIE have limitations. For instance, although there are significant seasonal variations in the consumption pattern, each round of the NSFIE covers only three months of the year (i.e., from September to November). Therefore, familial transfers in the form of wedding gifts, monetary contributions in case of death, financial assistance for university tuitions and housing, and so forth, may be rather poorly captured in the survey, which makes the estimates of familial transfers less reliable. Despite these data limitations, adult children are almost certainly contributing substantially less to their elderly parents through familial transfers than in 1984.

\section{References}

Bloom, D., and J. Williamson. 1998. Demographic transitions and economic miracles in emerging Asia. World Bank Review 12:419-56.

Clark, R., N. Ogawa, S.-H. Lee, and R. Matsukura. 2008. Older workers and national productivity in Japan. Population Development Review 34 (Supplement): S257-S274. 
Ermisch, J. 2003. An economic analysis of the family. Princeton, NJ: Princeton University Press.

Gollin, D. 2002. Getting income shares right. Journal of Political Economy 110: 458-74.

Hodge, R., and N. Ogawa. 1991. Fertility change in contemporary Japan. Chicago: University of Chicago Press.

International Institute for Management Development. 2008. IMD World Competitiveness Yearbook 2008. Lausanne, Switzerland: IMD.

Japan Institute of Labour Policy and Training. 2004. Law Concerning Stabilization of Employment of Older Persons. Law no. 103 of June 11, 2004.

Lee, R., and A. Mason. 2009. Fertility, human capital, and economic growth over the demographic transition. European Journal of Population (published online on June 19).

Lutz, W., W. Sanderson, and S. Scherbov. 2004. The end of world population growth in the 21st century: New challenges for human capital formation and sustainable development. London and Sterling, VA: Earthscan.

Mason, A., ed. 2001. Population change and economic development in East Asia: Challenges met, and opportunities seized. Stanford: Stanford University Press.

. 2007. Demographic transition and demographic dividends in developed and developing countries. United Nations Expert Group Meeting on Social and Economic Implications of Changing Population Age Structures. 31 August2 September, 2005, Mexico City. New York: United Nations, pp. 81-102.

Mason, A., and R. Lee. 2006. Reform and support systems for the elderly in developing countries: Capturing the second demographic dividend. Genus 62 (2): 11-35.

. 2007. Transfers, capital, and consumption over the demographic transition. In Population Aging, Intergenerational Transfers and the Macroeconomy, eds. R. Clark, N. Ogawa, and A. Mason, 128-62. Northampton, MA: Edward Elgar.

MacKellar, L. 2003. The predicament of population aging: A review essay. Vienna Yearbook of Population Research 2003:73-99.

McDonald, P. 2009. Explanations of low fertility in East Asia in comparative perspective. In Ultra-low fertility in Pacific Asia: Trends, causes and policy issues, ed. G. Jones, P. Straughan, and A. Chan, 23-39. Abington, Oxon: Routledge.

Matsukura, R., N. Ogawa, and R. L. Clark. 2007. Analysis of employment patterns and the changing demographic structure of Japan. The Japanese Economy 34:82153.

National Institute of Population and Social Security Research. 2007. Social security benefits for fiscal year 2007. Published on the website of the National Institute of Population and Social Security Research Institute, http://www.ipss.go.jp/.

Organization for Economic Cooperation and Development (OECD). 2005. Recommendation on principles and good practices for financial education and awareness. Paris: OECD. 2007. OECD health DATA 2007. Paris: OECD.

Ogawa, N., and J. Ermisch. 1996. Family structure, home time demands, and the employment patterns of Japanese married women. Journal of Labor Economics 14:677-702.

Ogawa, N., M. Kondo, M. Tamura, R. Matsukura, T. Saito, A. Mason, S. Tuljapurkar, and N. Li. 2003. Long-term perspectives for Japan: An analysis based on a macroeconomic-demographic-social security model with emphasis on human capital. Tokyo: Nihon University Population Research Institute.

Ogawa, N., S.-H. Lee, and R. Matsukura. 2005. Health and its impact on work and dependency among the elderly in Japan. Asian Population Studies 1:121-45.

Ogawa, N., A. Mason, Maliki, R. Matsukura, and K. Nemoto. 2007. Population 
aging and health care spending in Japan: public- and private-sector responses. In Population aging, intergenerational transfers and the macroeconomy, eds. R. Clark, N. Ogawa, and A. Mason, 192-223. Northampton, MA: Edward Elgar.

Ogawa, N., and R. Matsukura. 2007. Ageing in Japan: The health and wealth of older persons. United Nations Expert Group Meeting on Social and Economic Implications of Changing Population Age Structures. 31 August-2 September, 2005, Mexico City. New York: United Nations, 199-220.

Ogawa, N., and R. Retherford. 1993. The resumption of fertility decline in Japan: 1973-92. Population and Development Review 19 (4): 703-41.

-1997. Shifting costs of caring for the elderly back to families in Japan. Population Development Reviews 23 (1): 59-94.

Ogawa, N., R. D. Retherford, and R. Matsukura. 2009. Japan's declining fertility and policy responses. In Ultra-low fertility in Pacific Asia: Trends, causes and policy issues, ed. G. Jones, P. Straughan, and A. Chan, 40-72. Abington, Oxon: Routledge.

Population Problems Research Council. 2004. National survey on population, families and generations. Tokyo: Mainichi Newspapers.

Retherford, R. D., and N. Ogawa. 2006. Japan's baby bust: Causes, implications, and policy responses. In The baby bust: Who will do the work? Who will pay the taxes? ed. F. R. Harris, 5-47. Lanham: Rowman \& Littlefield Publishers, Inc.

Sakamoto, J. 2005. Population challenges and social security - the case of Japan. Paper presented at the Forum on Population and Development in East Asia. 16-17 May, Beijing, China.

The Asahi Shimbun. 2007. Life insurance premiums to drop in April, March 10.

The Nikkei. 2007. Law prompts banks to heighten protection for elderly customers, October 1.

The Nikkei. 2008a. Annuity, medical insurance contracts top life policies, June 24. The Nikkei. 2008b. 57\% say pension payouts not enough for living expenses, May 13. United Nations. 2007. World population prospects: The 2006 revision. New York: United Nations.

Washington Post. 2008. Japan steadily becoming a land of few children, May 6. Yoshikawa, H. 2001. Japan's lost decade. Tokyo: International House of Japan.

\section{Comment Worawan Chandoevwit}

The main objective of this chapter is to study the impact of population aging on both public and private intergenerational transfers in Japan in the last two decades. The highlights of the chapter are the last two sections relating to: (a) population aging, (b) intergeneration transfers, (c) two demographic dividends and changing pattern of lifecycle deficits, and (d) life cycle reallocations. The result from the last part is quite interesting.

This chapter systematically elaborates the facts about a rapid demographic transition, and changes of social security expenditure and family support. Generally, many of us know that Japan has already moved into aging population, but this chapter shows how it had evolved.

Worawan Chandoevwit is research director of the Thailand Development Research Institute. 